УДК 550.832

\title{
АЛГОРИТМЫ ОБРАБОТКИ И ИНВЕРСИИ ДАННЫХ ЭЛЕКТРОМАГНИТНОГО ЗОНДА С ТОРОИДАЛЬНЫМИ КАТУШКАМИ ПРИ ИЗУЧЕНИИ МАКРОАНИЗОТРОПНЫХ СВОЙСТВ ПЛАСТОВ-КОЛЛЕКТОРОВ
}

\author{
Эпов Михаил Иванович', \\ EpovMl@ipgg.sbras.ru \\ Михайлов Игорь Владиславович', \\ MikhaylovIV@ipgg.sbras.ru \\ Глинских Вячеслав Николаевич', \\ GlinskikhVN@ipgg.sbras.ru \\ Никитенко Марина Николаевна', \\ NikitenkoMN@ipgg.sbras.ru \\ Суродина Ирина Владимировна², \\ sur@ommfao1.sscc.ru \\ 1 Институт нефтегазовой геологии и геофизики им. А.А. Трофимука СО РАН, \\ Россия, 630090, г. Новосибирск, пр. Академика Коптюга, 3. \\ 2 Институт вычислительной математики и математической геофизики СО РАН, \\ Россия, 630090, г. Новосибирск, пр. Академика Лаврентьева, 6.
}

\begin{abstract}
Актуальность исследования обусловлена необходимостью разработки базовых алгоритмов обработки и инверсии данных нового многокатушечного многочастотного мультирежимного электромагнитного зонда с тороидальными катушками, предназначенного для изучения электрической макроанизотропии горных пород, определения характера насыщения пород-коллекторов, выделения тонкослоистых песчано-глинистых нефтенасыщенных интервалов и зон трещиноватости.

Цель: разработать базовые алгоритмы обработки и инверсии данных нового электромагнитного зонда с тороидальными катушками для изучения макроанизотропных свойств пластов-коллекторов сложного геологического строения (тонкослоистых, трещиноватых).

объекты: сигналы нового электромагнитного зонда с тороидальными катушками.

Методы: численное моделирование на основе сеточного метода конечных разностей и сравнительный анализ сигналов нового электромагнитного зонда с тороидальными катушками.

Результаты. Разработаны базовые алгоритмы обработки и инверсии данных нового электромагнитного зонда с тороидальными катушками. Среди них: алгоритмы трансформации сигналов в кажущееся удельное электрическое сопротивление и коэффициент электрической анизотропии, выделения контрастных геоэлектрических границ, а также программные средства численной инверсии с определением параметров изотропного и анизотропного пласта с учётом удельного электрического сопротивления вмещающей среды. Вычислительные алгоритмы объединены в единую компьютерную программу количественной интерпретации данных нового электромагнитного зонда с тороидальными катушками. Выполнено тестирование алгоритмов на зашумлённых синтетических данных, и показана их эффективность при обработке практических данных из разрезов нефтегазовых скважин в Волго-Уральской нефтегазоносной провинции. Выполненные исследования демонстрируют, что новый электромагнитный зонд с тороидальными катушками имеет высокий потенциал для применения в геологических разрезах сложного строения.
\end{abstract}

\section{Ключевые слова:}

Геофизические исследования в скважинах, тороидальные катушки, удельное электрическое сопротивление, электрическая анизотропия, численная инверсия, сложнопостроенный коллектор, нефтенасыщение.

\section{Об изучении макроанизотропных свойств пластов-коллекторов}

Вовлечение в изучение и разработку новых типов нефтегазовых залежей приводит к расширению круга задач промысловой геофизики. Одна из них связана с нефтенасыщенными коллекторами, представленными тонким переслаиванием песчаных и глинистых прослоев.

Удельное электрическое сопротивление (УЭС) основная электрофизическая характеристика горных пород, по которой определяется тип насыщения (газ, нефть или вода). Как известно, УЭС нефтенасыщенного коллектора всегда выше, чем водо- насыщенного. Однако такое соотношение соблюдается не всегда, например, при наличии глинистых минералов в горных породах УЭС коллектора невысокое, в частности, в тонкослоистом песчаноглинистом. При этом он может содержать значительное количество нефтенасыщенных прослоев.

Определение УЭС пластов выполняется по измерениям на постоянном и переменном токах. Оценка УЭС и мощности отдельных прослоев тонкослоистого коллектора не представляется возможной, в силу их большого числа. Поэтому разделение по типу насыщения выполняют, определяя значения горизонтального $\left(\rho_{h}\right)$ и вертикального 
$\left(\rho_{v}\right)$ УЭС или коэффициента электрической анизотропии $\lambda=\sqrt{\frac{\rho_{v}}{\rho_{h}}}$. Соотношение электрических и электромагнитных сигналов в тонкослоистой и макроанизотропной среде исследовано С.М. Рытовым [1]. Л.М. Альпиным показано, что при субвертикальном пересечении скважиной тонкослоистого пласта измеренные электрокаротажные сигналы зависят только от горизонтального УЭС $[2,3]$. Поэтому полученные при стандартной интерпретации данных в тонкослоистых коллекторах значения УЭС будут значительно занижены по сравнению со значениями в нефтенасыщенных прослоях и будут соответствовать водонасыщенным песчаникам. Так, в последующем с увеличением числа неучтённых глинистых прослоев возрастает ошибка определения подсчётных запасов углеводородов по данным УЭС стандартных приборов каротажа.

Традиционно параметры макроанизотропного коллектора определяют по измерениям многокомпонентными зондами с ортогональными катушками [4]. Такие зондовые системы используются ведущими зарубежными компаниями Baker Hughes GE, Halliburton, Schlumberger, Weatherford. Taк, трёхкомпонентные измерения известными приборами Rt Scanner (Schlumberger) и 3D eXplorer (Baker Hughes GE), в отличие от измерений зондами индукционного каротажа, широко используются для выявления и оценки нефтенасыщения электрически макроанизотропных коллекторов, в том числе уже упомянутых выше низкоомных, а также трещиноватых карбонатов и глинистых покрышек [5]. Из практики известно, что с использованием стандартных методов некоторые нефтенасыщенные толщи и вовсе пропускаются, поскольку, как уже отмечалось, интерпретируются как водонасыщенные [6]. Однако такие специальные многокомпонентные системы редко используются в отечественной практике и к тому же требуют привлечения ресурсоемких вычислительных схем и процедур интерпретации, что снижает эффективность их применения. Также известны другие разработки по моделированию нового каротажного зонда для определения коэффициента электрической анизотропии пород, в котором источником сигнала является магнитный диполь, а измеряется напряжение одной из компонент электрического поля в короткой измерительной линии [7].

Изучение электрической макроанизотропии геологической среды возможно также с использованием тороидальных катушек (замкнутого соленоида), но их применение в каротаже для определения УЭС горных пород и коэффициента электрической анизотропии, в том числе в процессе бурения, малоизвестно. Работа Ј.J. Arps наиболее ран- няя [8]. В описанной им конфигурации используются две генераторные катушки и две измерительные, симметрично расположенные между ними на металлическом корпусе зонда. В это же время Д.С. Даев математически описывает источник в виде кругового магнитного тока, соответствующего тороидальной катушке [9]. Дальнейшее развитие при изучении как вертикальных, так и горизонтальных скважин нашло своё отражение в работе S. Gianzero с коллегами [10]. Идея азимутальных измерений также реализована с использованием тороидальных катушек, расположенных на корпусе зонда, которые обеспечивают построение электрических имиджей [11]. Возможности определения электрической макроанизотропии с помощью тороидальных катушек исследовались рядом учёных [12-15], в то время как более поздние работы посвящены повышению разрешающей способности каротажных зондов с тороидальными катушками [16].

\section{Новый электромагнитный зонд}

\section{с тороидальными катушками}

На основе ряда новых теоретико-методических и инженерно-технических идей предложен, спроектирован, разработан и апробирован зонд электромагнитный с тороидальными катушками (ЗЭТ) с высоким пространственным разрешением $[17,18]$. Многокатушечный многочастотный мультирежимный зонд состоит из цилиндрического металлического немагнитного корпуса, двух генераторных катушек, нескольких измерительных тороидальных катушек, размещённых на корпусе $[19,20]$. Тороидальные катушки расположены симметрично относительно центра зонда длиной 1,0 м, используемые частоты - 50, 100, 250 кГц (рис. 1). Благодаря высокой удельной электропроводности металла плотность поверхностного тока значительна даже при невысоких значениях моментов генераторных катушек.

ЗЭТ имеет оригинальную систему возбуждения-наблюдения. Реализуются два режима: суммарный режим, в котором токи в генераторных катушках равны между собой и сонаправлены, и дифференциальный режим, где они равны и противоположны по знаку (рис. 2). Первый режим применяется для выделения границ пластов в вертикально-неоднородном разрезе, определения пространственного распределения УЭС и коэффициента электрической анизотропии, а второй - для выделения границ и зон трещиноватости.

От тороидального источника на металлическом корпусе в геологической среде возбуждается переменное электрическое поле, которое имеет как горизонтальную, так и вертикальную компоненты. Вследствие этого регистрируемые сигналы зависят

Puc. 1. Фото ЗЭТ

Fig. 1. Photo of the electromagnetic tool with toroidal coils (TTC) 
не только от горизонтального, но и от вертикального УЭС пересекаемого скважиной пласта (рис. 3). Выполняются измерения реальной и мнимой частей плотности тока, протекающего по корпусу прибора. ЗЭТ разработан для изучения электрической макроанизотропии горных пород, определения характера насыщения пород-коллекторов, выделения тонкослоистых песчано-глинистых нефтенасыщенных интервалов и зон трещиноватости.

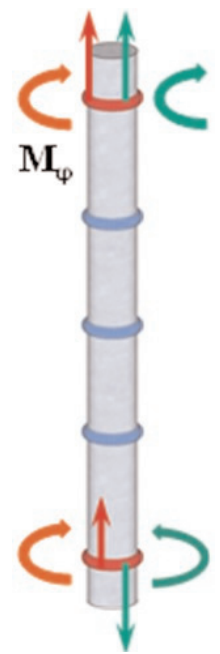

Рис. 2. Модель ЗЭТ. Слева - сум.марный режим, справа - дифференциальный режим

Fig. 2. TTC model. On the left-summary mode, on the right-differential mode

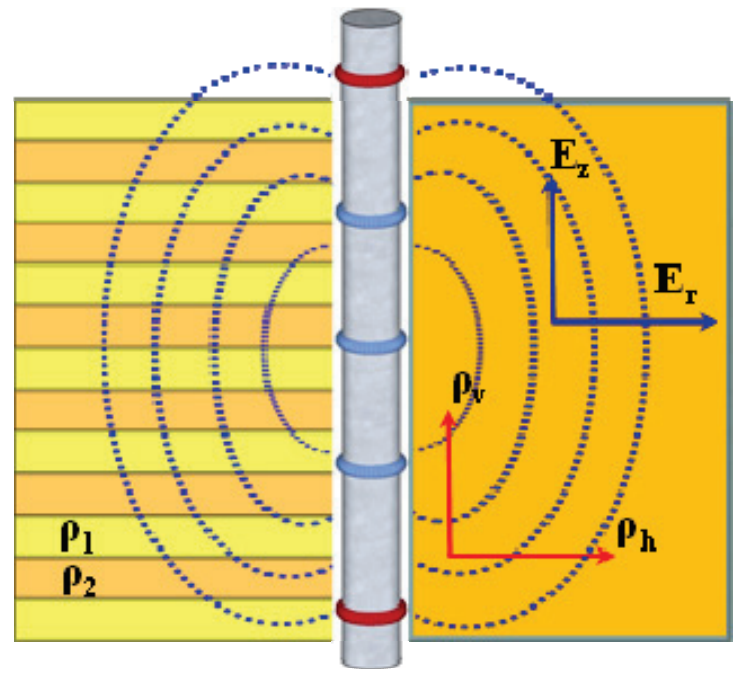

Рис. 3. ЗЭТ в модели тонкослоистого песчано-глинистого коллектора (слева) и эквивалентной макроанизотропной модели (справа)

Fig. 3. TTC in the model of a thin-layered sandy-argillaceous reservoir (left) and equivalent macroanisotropic model (right)

При интерпретации результатов измерения ЗЭТ используются двумерные модели геологической среды, в которых учитываются конечные размеры металлического корпуса. С привлечением современного математического аппарата разработаны базовые вычислительные алгоритмы для обработки и интерпретации данных ЗЭТ.

\section{Описание базовых вычислительных алгоритмов для обработки и интерпретации данных ЗЭТ}

Разработаны и программно реализованы алгоритмы трансформации сигналов в кажущееся УЭС и коэффициент электрической анизотропии, выделения контрастных геоэлектрических границ, численной инверсии с определением геоэлектрических параметров изотропного и анизотропного пласта, в том числе с учётом УЭС вмещающей среды (рис. 4).

Входными данными для программы численной инверсии являются амплитуды и фазы или реальные и мнимые части измеренных зондом сигналов в суммарном и дифференциальном режиме. Также на вход подаются УЭС бурового раствора и радиус скважины, и некоторые другие параметры, контролирующие работу программы. Выходными данными являются: границы пластов, трансформации сигналов (кажущееся УЭС и коэффициент электрической анизотропии) на разных частотах и результат двумерной инверсии - УЭС пластов, с учётом влияния УЭС вмещающих пород, также на разных частотах.

Алгоритмы протестированы в большом диапазоне параметров типичных геоэлектрических моделей пластов-коллекторов, с дальнейшей апробацией при обработке практических данных.

\section{Выделение границ изотропных пластов}

Геоэлектрические границы определяются по сигналам суммарного и дифференциального режимов по результатам анализа характерных экстремумов сигналов в результате их преобразований. Преобразования представляют собой разность или сумму сигналов, зарегистрированных на крайних измерительных катушках, нормированную на сигнал в центральной катушке, что является аналогом производной и среднего за счёт выбранной конфигурации зондовой системы. Определённые таким образом положения границ, соответствующие экстремумам на преобразованных сигналах по суммарному и дифференциальному режиму, сравниваются между собой и при совпадении в пределах нескольких отсчётов представляют собой окончательный результат по расстановке границ.

\section{Выделение границ анизотропных интервалов}

Выделение границ анизотропных интервалов производится по преобразованным сигналам суммарного режима тем же способом, что и описан выше. При этом используется следующий критерий: если в заданном окне по глубине имеется несколько прослоев мощностью меньшей, либо равной заданной (например, окно $1 \mathrm{~m}-5$ прослоев по 0,2 м), интервал является анизотропным. Реализован и другой вариант расстановки границ, в котором во всех точках выделенного интервала производится одновременное определение значений кажущегося УЭС и коэффициента электрической анизотропии, если анизотропные интервалы в явном виде не выделяются (например, если переслаивание слишком мелкое). 


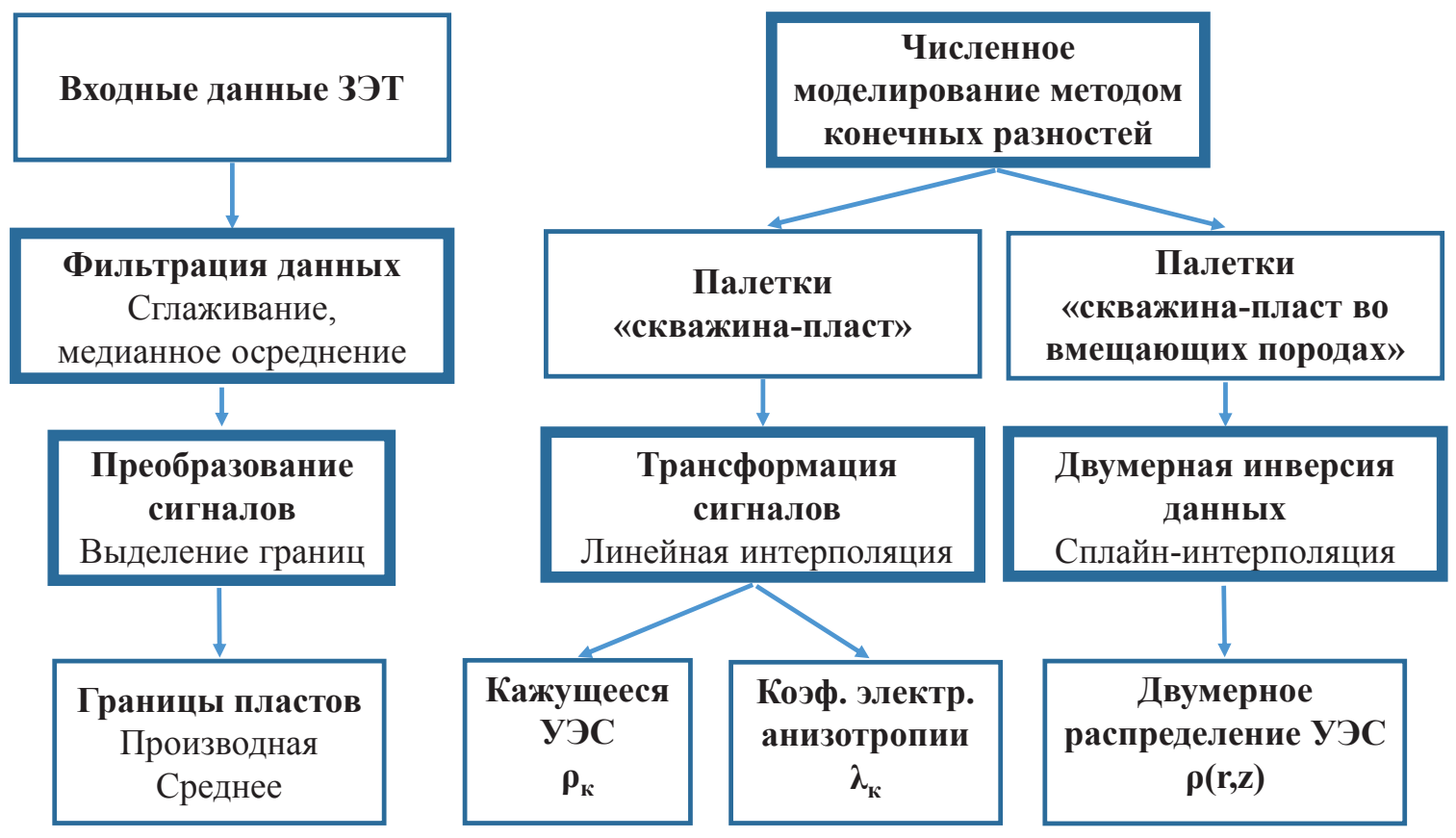

Рис. 4. Блок-схема вычислительных способов обработки и интерпретации результатов измерения ЗЭТ

Fig. 4. Block diagram of computational methods for processing and interpreting the results of TTC measurements

Трансформация в кажущееся УЭС на изотропных интервалах

Трансформация в кажущееся УЭС на изотропных интервалах выполняется поточечно, без учёта влияния УЭС вмещающих пород, с использованием палеток «скважина - изотропный пласт». Трансформация сигналов в кажущееся УЭС выполняется с помощью палеток, рассчитанных для разных УЭС и радиусов скважины с учётом конечных размеров металлического корпуса прибора. Для заданного значения УЭС бурового раствора скважины производится линейная интерполяция между значениями двух соседних узлов палеток. Подбираются такие значения УЭС пласта, чтобы расхождение между синтетическими и практическими данными было минимально.

\section{Трансформация в кажущееся УЭС и коэффициент электрической анизотропии на анизотропных интервалах}

Эта аналогичная трансформация также выполняется поточечно, без учёта влияния УЭС вмещающих пород с использованием палеток «скважина анизотропный пласт» при значениях коэффициента электрической анизотропии $\lambda$ от 1 до 4. Подбираются такие значения УЭС пласта и коэффициента электрической анизотропии, чтобы расхождение между синтетическими и практическими данными было минимально.

Численная инверсия для определения пространственного распределения УЭС пласта

Численная двумерная инверсия с определением УЭС производится для пластов, мощность кото- рых не превышает 3,0 м, с учётом УЭС вмещающих пород. Для ускорения вычисления рассчитаны палетки для различных значений УЭС пласта и вмещающих пород, являющихся входными данными для численной инверсии. Все палетки насчитаны с геометрическим шагом с использованием программы двумерного моделирования конечноразностным методом [21] с учётом корпуса прибора для мощностей пластов от 0,5 до 3,0 м.

С использованием вышеописанных палеток «скважина-пласт-вмещающая среда» выполняется двумерная инверсия данных после предварительного выделения границ пластов, с определением значений УЭС пласта. Выбирается пласт, находится его УЭС в предположении, что вмещающие породы сверху и снизу - полупространства. В качестве результата выбирается УЭС пласта, для которого выполняется инверсия, а УЭС вмещающих пород в результат не попадают.

Особенности алгоритма заключаются в следующем.

Во-первых, палетки рассчитываются для ряда глубин, симметрично расположенных относительно центра пласта. Если глубины практических данных не совпадают с рассчитанными, выполняется сплайн-интерполяция измеренных сигналов кубическими сплайнами в палеточные глубины. Во-вторых, линейная интерполяция палеточных данных выполняется по мощности пласта, если мощность выбранного пласта не совпадает с палеточной. Если мощность превышает максимальную $(3,0$ м), в качестве искомого УЭС берётся УЭС однородной среды по усреднённому значению в трёх средних точках пласта. Если мощность пласта меньше 0,5 м, 
используется палетка, соответствующая мощности 0,5 м. В-третьих, учитываются глубины, попадающие внутрь пласта и в его ближайшей окрестности, что значительно сокращает возможную эквивалентность. Выполняется отбрасывание лишних точек за пределами пласта, при этом сверху и снизу от границ пласта добавляется по одной точке. Иными словами, используется переменное число глубин в зависимости от мощности пласта.

Помимо этого, вычисляются существенные значения в виде средних пластовых значений по электропроводности для визуализации УЭС в разрезе в виде кусочно-постоянной функции.

\section{Тестирование основных вычислительных алгоритмов}

Проведённое тестирование основных вычислительных алгоритмов на синтетических данных, рассчитанных для типичных геоэлектрических ситуаций (терригенный песчано-глинистый разрез, карбонатный трещиноватый разрез) с изотропными и анизотропными пластами, демонстрирует их высокую эффективность.

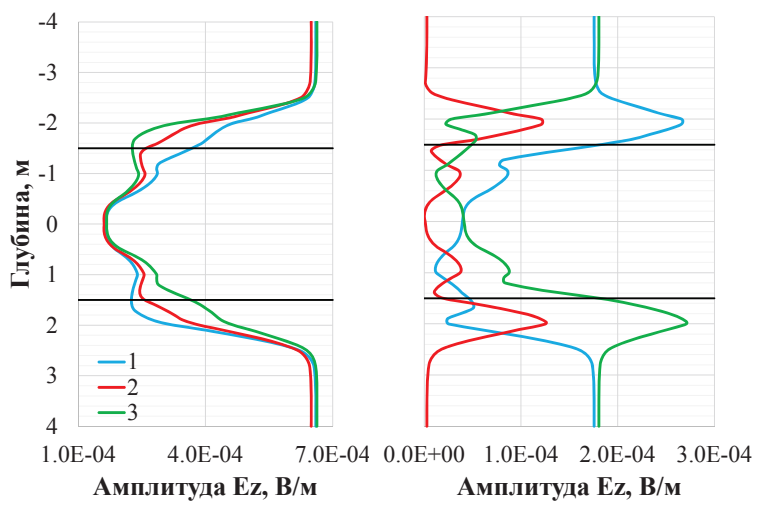

Pис.5. Диаграмлы сулмарного (слева) и дифференциального (справа) режилов ЗЭТ в модели нефтеводонасыщенного песчаника в глинистых отложениях. Операционная ча стота $100 \kappa Г$. ШІифр - расстояние от генераторной до приёмной катушки (м): 1) 0,25; 2 ) 0,5; 3) 0,75

Fig. 5. TTC logs in the summary (left) and differential (right) mo des in the model of an oil-saturated sandstone in argillaceous deposits. Frequency is $100 \mathrm{kHz}$. The key is the distance from the generator to receiving coil ( $m$ ): 1) 0,25;2) 0,5;3) 0,75

Из анализа диаграммы амплитуды вертикальной компоненты электрического поля в суммарном и дифференциальном режимах ЗЭТ в модели трёхметрового нефтеводонасыщенного песчаника (УЭС 10,0 Ом·м), залегающего в глинах (УЭС 1,0 Ом·м) (рис. 5), следует, что диаграммы суммарного режима отражают геоэлектрические условия флюидонасыщенного коллектора, а дифференциального - особенности перехода через границы. При этом диаграммы зонда 0,5 м симметричны относительно центра пласта, в то время как диаграммы зондов 0,25 и 0,75 м зеркально симметричны. Асимптотические значения сигналов достигаются на расстоянии около 1,0 м от границ пласта, при этом для зондов 0,25 и 0,75 м они совпадают. В центре пласта и на асимптотах значения сигна- лов суммарного режима близки между собой, в то время как при длине зонда 0,5 м сигнал дифференциального режима нулевой. Положение экстремумов смещено относительно границ на 0,5 м, при этом два ближайших измерителя показывают максимальные значения, а удалённый - минимальное. Это справедливо для всех рассмотренных частот и различных контрастов электрофизических параметров в симметричных моделях.

Из анализа преобразованных диаграмм суммарного и дифференциального режимов для автоматического выделения геоэлектрических границ (координаты $-1,5$ и 1,5 м) (рис. 6) следует, что границы выделены с высокой степенью локальности: ошибка не превышает одного отсчёта по глубине.

Результаты масштабного численного моделирования сигналов ЗЭТ показывают, что минимальная толщина пласта, надёжно выделяемого по его данным, составляет 0,5 м.

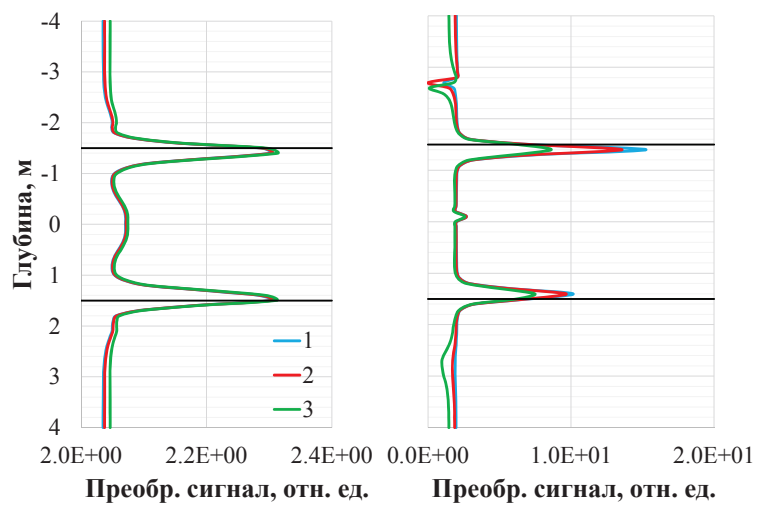

Pис.6. Выделение грании по преобразованныл диаграмлал суммарного (слева) и дифференииального (справа) режимов ЗЭТ в модели нефтеводонасыщенного песчаника в глинистых отложениях. Шифр - операционная частота (кГu): 1) 50; 2) 100;3) 250

Fig. 6. Detection of boundaries from the transformed logs of the summary (left) and differential (right) TTC modes in the model of an oil-saturated sandstone in argillaceous deposits. The key is frequency ( $\mathrm{kHz}$ ): 1) 50;2) 100;3) 250

В модели сложнопостроенного контрастного геологического разреза мощности пластов изменяются в диапазоне $0,2-4,0$ м, УЭС - от 1,5 до 150 Ом·м (рис. 7 справа, чёрным цветом). Из анализа результата автоматической двумерной инверсии (лиловый цвет) следует, что наибольшие погрешности восстановления УЭС (12,0 и $33,5 \%)$ наблюдаются на интервалах $0-4,0$ и 7,4-8,0 м, соответственно. В первом случае она обусловлена дискретностью палеточных значений УЭС для ускорения расчётов, а во втором - влиянием низкоомных вмещающих отложений на сигнал в маломощном пласте. Наибольшая погрешность восстановления границы - на интервале 0-4,0 м, где полученная координата нижней границы - 3,5 м, что обусловлено влиянием нижезалегающего пропластка с пониженным УЭС. В ходе автоматической двумерной инверсии восстановлены все основные особенности геоэлектрического разреза. 


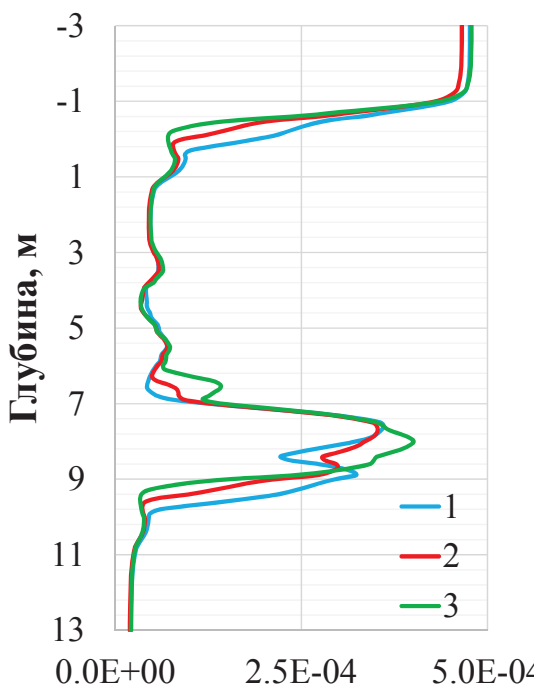

Амплитуда Ez, B/м

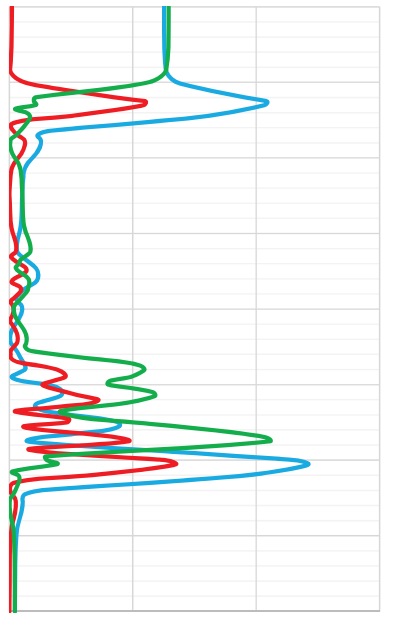

Амплитуда Ez, B/м

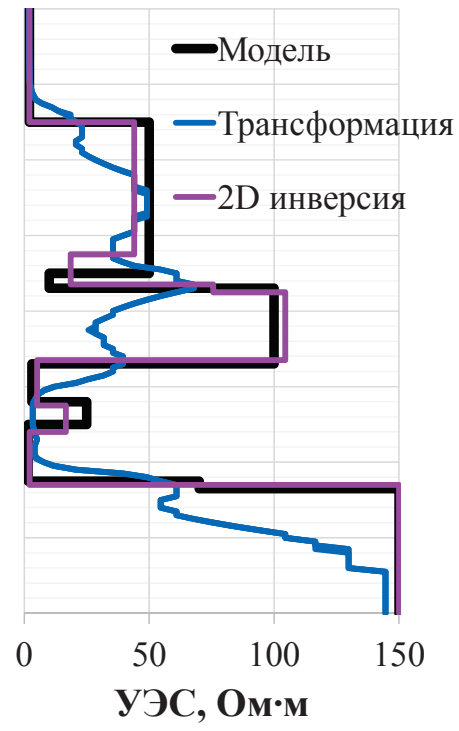

Рис. 7. Диагралмы ЗЭТ в сулмарном (слева) и дифференииальном (по иентру) режилах и результаты трансфорлации и двулерной инверсии (справа) в модели сложнопостроенного геологического разреза. Шифр слева-расстояние от генераторной до приёмной катушки

Fig. 7. TTC logs in the summary (left) and differential (center) modes and the results of transformation and two-dimensional inversion (right) in the model of a complex geological section. Left key is the distance from the generator to receiving coil

Синим цветом показан результат трансформации сигналов в значения кажущегося УЭС на разных частотах. Наибольшие различия от результата двумерной инверсии отмечаются в маломощных пластах $(4,0-4,4 ; 7,4-8,0$ м), а также в более мощном пласте $(4,4-6,4 \mathrm{~m})$, в котором существенное влияние на сигнал оказывают проводящие вмещающие породы. Небольшие расхождения между истинным и восстановленным УЭС на интервале нижней асимптоты объясняются дискретностью палеточных значений.

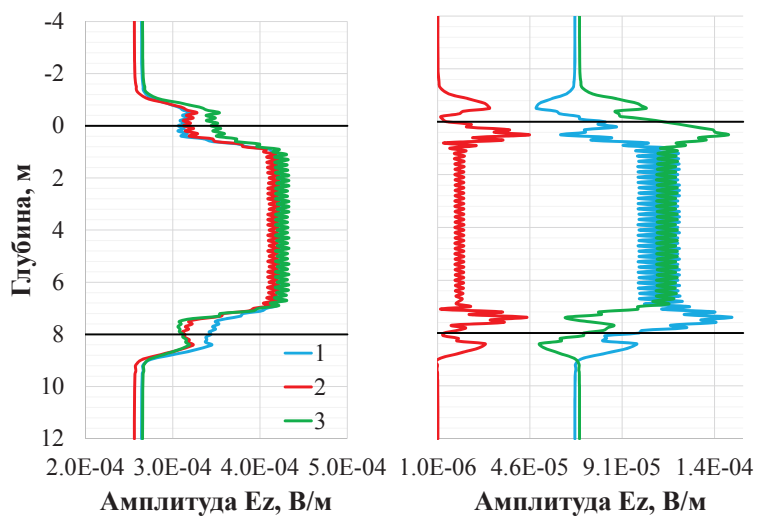

Pис. 8. Диагралмы ЗЭТ в сулмарном (слева) и дифференииаль ном (справа) режилах в модели тонкослоистого песчаноглинистого коллектора в аргиллитах. Операционная ча стота 100 кГи. Шифр - расстояние от генераторной до приёмной катушки

Fig. 8. TTC logs in the summary (left) and differential (right) modes in the model of a thin-bedded sandy-argillaceous reservoir in argillites. Frequency is $100 \mathrm{kHz}$. The key is the distance from the generator to receiving coil
Для оценки возможности определения параметров макроанизотропных коллекторов на рис. 8 представлены результаты моделирования сигналов ЗЭТ в модели тонкослоистого песчано-глинистого коллектора (УЭС песчаника 10,0 Ом·м, УЭС глин 1,0 Ом·м, мощности пропластков $0,1 \mathrm{~m})$, залегающего в аргиллитах (УЭС 5,0 Ом·м) и характеризующегося макроанизотропными свойствами (горизонтальное УЭС 1,82 Ом·м, коэффициент электрической анизотропии 1,74$)$. Границы коллектора имеют координаты 0,0 и 8,0 м. На рисунке видно, что маломощные пропластки проявляются на всех диаграммах ЗЭТ характерной периодичностью.

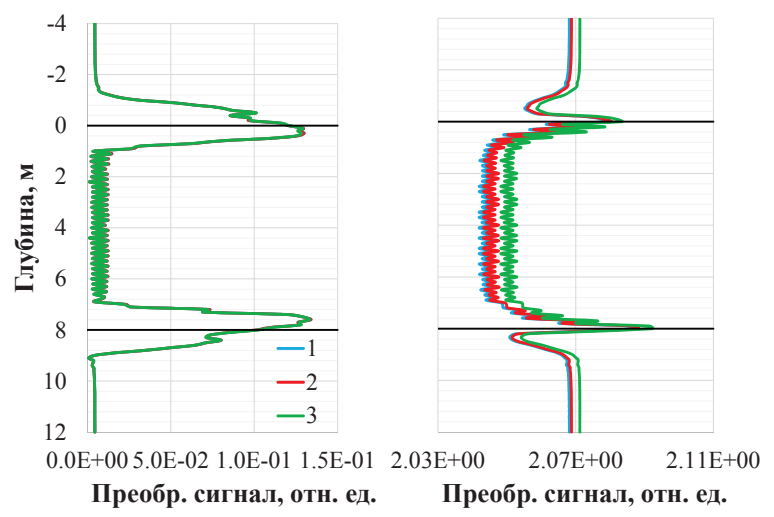

Рис.9. Выделение грании по преобразованным диаграмлал суммарного режила ЗЭТ в модели тонкослоистого песчаноглинистого коллектора в аргиллитах. Шифр - операционная частота

Fig. 9. Detection of boundaries from the transformed logs of the TTC summary mode in the model of a thin-layered sandy-argillaceous reservoir in argillites. The key is frequency 
По преобразованным диаграммам суммарного режима и автоматически выделенным границам анизотропного интервала (рис. 9) видно, что границы выделены с высокой степенью локальности: ошибка не превышает двух отсчётов по глубине.

На рис. 10 чёрным цветом показаны модельные распределения горизонтального УЭС, определяемого традиционными методами скважинной электрометрии (ВИКИЗ, БК, ИК) (слева), и коэффициента анизотропии (справа), а цветами - их медианно осреднённые и восстановленные в ходе трансформации значения. Горизонтальное УЭС восстановлено с ошибкой не более 5,0 \%, а коэффициент анизотропии - не более $3,5 \%$. Выход на асимптотические значения, соответствующие вмещающим аргиллитам, происходит на расстоянии около 1,5 м от границ.
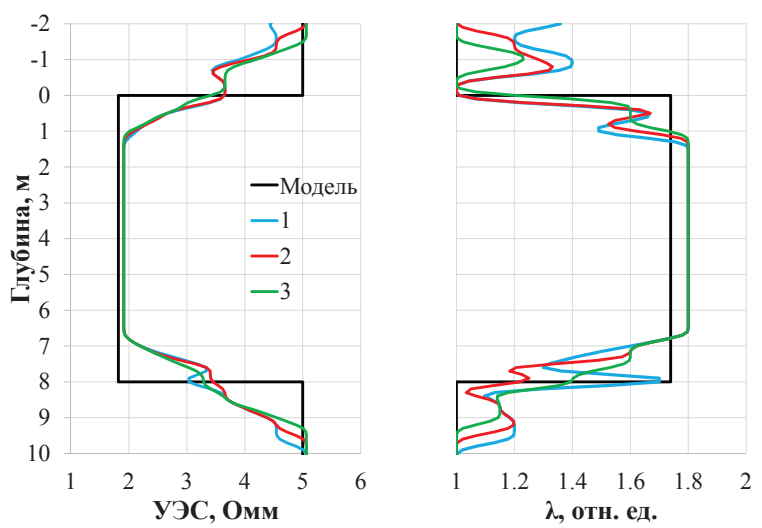

Рис. 10. Результаты трансфорлации излеряелых сигналов ЗЭТ в горизонтальное УЭС (слева) и коэффиииент әлектри ческой анизотропии (справа). Шифр - операционная ча cmoma

Fig. 10. Results of transformation of the measured TTC signals to the horizontal resistivity (left) and electrical anisotropy coefficient (right). The key is frequency

Погрешность определения геоэлектрических параметров в зависимости от уровня шума в регистрируемых сигналах ЗЭТ в геоэлектрических моделях разной степени сложности будет изучена в дальнейших исследованиях.

\section{Обработка и двумерная инверсия практических данных ЗЭТ}

Для апробации разработанных алгоритмов на практических диаграммах выполнена обработка и двумерная инверсия данных ЗЭТ из скважины с месторождения Самарской области (Волго-Уральская нефтегазоносная провинция), вскрывшей разрез сложного геологического строения, включающего как терригенные, так и карбонатные отложения.

Анализируются диаграммы амплитуды тока в суммарном и дифференциальном режимах на интервале переслаивания глин и песчаников (рис. 11). По дифференциальному режиму отмечается более высокая степень расчленения геоэлектрического разреза. Диаграммы суммарного режи- ма характеризуются наибольшими значениями в интервале $\times \times 25,0-\times \times 33,0 \mathrm{~m}$, который является нижней частью мощного глинистого пласта.

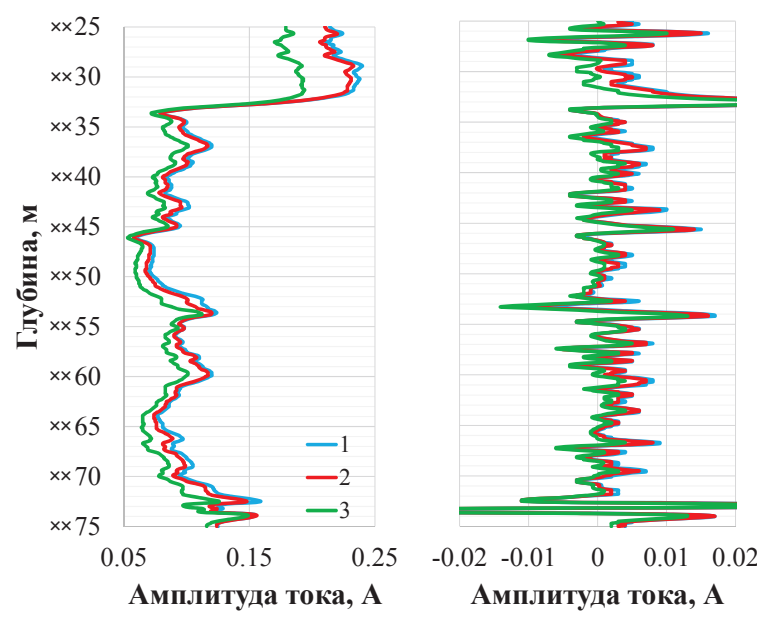

Рис.11. Практические диаграмль ЗЭТ в сумларном (слева) и дифференииальном (справа) режимах из скважины Самарской области на интервале тонкого переслаивания глин и песчаников. Шифр - операционная частота

Fig.11. TTC practical logs in the summary (left) and differential (right) modes from a borehole in Samara Region at the interval of thin lamination of argillaceous deposits and sandstones. The key is frequency

К диаграммам суммарного и дифференциального режимов применён алгоритм автоматического выделения геоэлектрических границ (рис. 12, чёрным слева). В случае необходимости более плотного выделения границ предусмотрена возможность задания другого числового критерия.

При анализе результатов транссормации в кажущееся УЭС и коэффициент электрической анизотропии, а также результатов двумерной инверсии (рис. 12), отмечается, что ниже отметки $\times \times 33,0$ м УЭС изменяется в диапазоне от 5 до 15 Ом·м, а коэффициент электрической анизотропии - от 1,0 до 2,5 отн. ед. Изменение последнего вызвано тонким переслаиванием различной литологии (глин и песчаников), причём повышенные значения приурочены к нефтенасыщению. Это подтверждается результатами испытания скважины на рассматриваемом интервале, предоставленными нефтедобывающим предприятием. Различие результатов трансформации в кажущееся УЭС и коэффициент электрической анизотропии, а также двумерной инверсии на разных частотах объясняется влиянием зоны проникновения фильтрата бурового раствора на представленном интервале. В целом отмечается высокая степень корреляции результатов трансформации в кажущееся УЭС и двумерной инверсии.

\section{Заключение}

По результатам численных исследований для нового многокатушечного многочастотного мультирежимного электромагнитного зонда с тороидальными катушками ЗЭТ разработаны алгорит- 


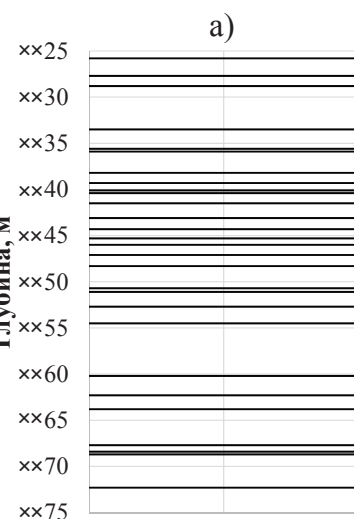

Геоэлектрич. границы б)

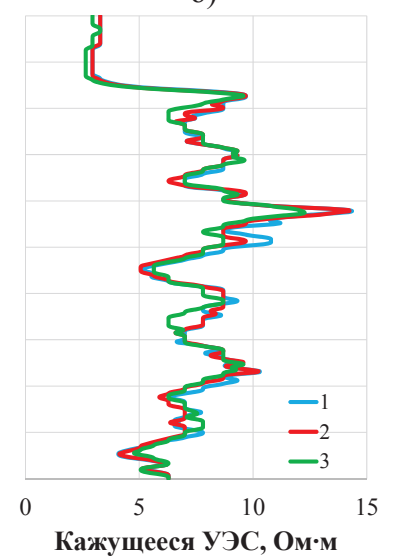

в)

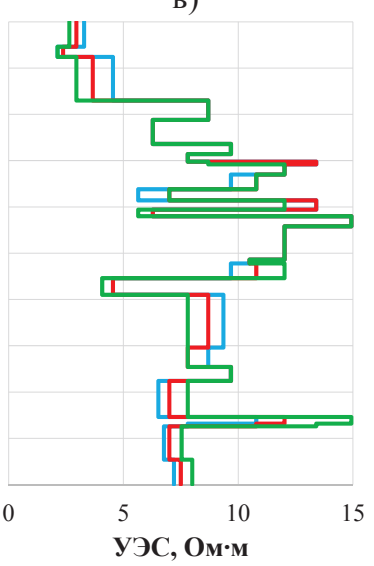

г)

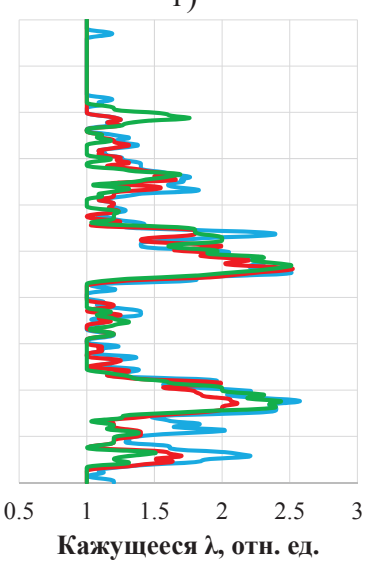

Рис. 12. Результаты автолатического выделения грании (а), трансфорлащии в кажущееся УЭС (б), двумерной инверсии (в) и определения коэффициента электрической анизотропии (г) по данныл ЗЭТ на интервале маломощных глинистых песчаников из скважины Самарской области. Шифр - операционная частота

Fig. 12. Results of automatic selection of boundaries (a), transformation into the apparent resistivity (б), two-dimensional inversion ( 8 ) and determination of the electrical anisotropy coefficient (2) according to TTC data at the interval of thin argillaceous sandstones from the borehole in Samara Region. The key is frequency

мы трансформации сигналов в кажущиеся УЭС и коэффициент электрической анизотропии, выделения контрастных геоэлектрических границ, а также программные средства численной инверсии с определением параметров изотропного и анизотропного пласта с учётом УЭС вмещающей среды. Выполнено тестирование алгоритмов на синтетических данных, и показана их эффективность при обработке практических данных из разрезов скважин в Волго-Уральской нефтегазоносной провинции. Вычислительные алгоритмы объединены в единую компьютерную программу количественной интерпретации данных электромагнитного зонда с тороидальными катушками. Результатами показано, что для выделения геоэлектрических границ с высокой степенью локальности необходимо совместно использовать диаграммы суммарного и дифференциального режимов. Диаграммы суммарного режима применяются для определения электрофизических характеристик флюидонасы-

\section{СПИСОК ЛИТЕРАТУРЫ}

1. Рытов С.М. Электромагнитные свойства мелкослоистой среды // Журнал экспериментальной и теоретической физики. 1955. - T. 29. - Вып. 5. - С. 605-616.

2. Альпин Л.М. Определение поперечного удельного сопротивления пластов по измерениям в скважинах // Известия вузов. Геология и разведка. - 1978. - № 4. - С. 81-95.

3. Альпин Л.М., Великин С.А. Определение анизотропии по измерениям в скважинах // Известия вузов. Геология и разведка. - 1983. - № 12. - С. 97-99.

4. Anderson B., Barber T., Habashy T. The Interpretation and Inversion of Fully Triaxial Induction Data: A Sensitivity Study // Transactions of the SPWLA $43^{\text {rd }}$ Annual Logging Symposium. Oiso, Japan, June 2-5, 2002. - Paper 0.

5. Triaxial Induction Applications in Difficult and Unconventional Formations / G. Wang, P. Wu, T. Barber, C. Johnson, D. Allen, щенных коллекторов. Параметры сложнопостроенного контрастного геологического разреза восстанавливаются в ходе трансформации и двумерной инверсии с достаточной для практических задач точностью. Выполненные исследования показывают, что новый электромагнитный зонд с тороидальными катушками имеет высокий потенциал для применения в геологических разрезах сложного строения (тонкослоистых, трещиноватых). В дальнейшем планируется усовершенствование системы количественной интерпретации данных ЗЭТ, включающее оптимизацию дискретизации палеточных узлов, учёт зоны проникновения и оценку ошибки определения геоэлектрических параметров. Другой аспект исследования связан с изучением возможностей ЗЭТ в наклонно-горизонтальных скважинах, в том числе при решении задач геонавигации.

Научные исследования выполнены при поддержке РФФИ (проект № 19-05-00595).

A. Kumar, W. Xu, R. Hayden // Transactions of the SPWLA $53^{\text {rd }}$ Annual Logging Symposium. - Cartagena, Colombia, June 16-20, 2012. - Paper G.

6. Using Multicomponent Induction Log Data to Enhance Formation Evaluation in Deepwater Reservoirs from Campos Basin, Offshore Brasil / R. Gomes, P. Denicol, A. da Cunha, M. de Souza, B. Kriegshäuser, C. Payne, A. Santos // Transactions of the SPWLA 43 $3^{\text {rd }}$ Annual Logging Symposium. - Oiso, Japan, June 2-5, 2002. - Paper N.

7. Каринский А.Д., Красносельских А.А. Моделирование каротажного зонда, предназначенного для определения коэффициента электрической анизотропии пород // Геофизика. 2016. - № 1. - C. 26-33.

8. Arps J. Inductive Resistivity Guard Logging Apparatus Including Toroidal Coils Mounted on a Conductive Stem. US Patent № 3305771; Publ. 21.02.67. 
9. Даев Д.С. Об источнике электромагнитного поля при высокочастотных измерениях в скважине // Известия АН СССР. Серия Физика Земли. - 1968. - № 11. - С. 94-95.

10. A New Resistivity Tool for Measurement-While-Drilling / S. Gianzero, R. Chemali, Y. Lin, S. Su, M. Foster // Transactions of the SPWLA $26^{\text {th }}$ Annual Logging Symposium. - Dallas, Texas, USA, June 17-20, 1985. - Paper A.

11. Measurements at the Bit: a New Generation of MWD Tools S. Bonner, T. Burgess, B. Clark, D. Decker, J. Orban, B. Prevedel, M. Luling, J. White // Oilfield Review. - April/July 1993. P. 44-54.

12. Gianzero S. The Paradox of Anisotropy Revisited // The Log Analyst. - 1999. - V. 40. - № 6. - P. 485-491.

13. Каринский А.Д. Решения прямых задач 0 поле тороидальной антенны в анизотропной среде // Физика Земли. - 2003. № 1. - C. 9-20.

14. Каринский А.Д., Мусатов А.А. Определение вертикального сопротивления пластов зондами с тороидальными антеннами при каротаже в процессе бурения // Новые идеи в науках о Земле: Тезисы VI международной конференции. - М., 2003. T. 2. - C. 357.

15. Bittar M.S., Hu G. The Effects of Rock Anisotropy on LWD Toroidal Resistivity Sensors // Transactions of the SPWLA $45^{\text {th }} \mathrm{An}$ nual Logging Symposium. - Noordwijk, the Netherlands, June 6-9, 2004. - Paper WW.

16. New Azimuthal Resistivity and High-Resolution Imager Facilitates Formation Evaluation and Well Placement of Horizontal Slim Boreholes / L. Ortenzi, I. Dubourg, R. van 0s, S. Han, R. Koe- psell, S. Chow Yuk Ha // Petrophysics. - 2012. - V. 53. - № 3. P. 197-207.

17. Способ измерения удельной электропроводности и электрической макроанизотропии горных пород: пат. Рос. Федерация № 2525149; заявл. 23.04.13; опубл. 10.08.14. - Бюл. № 22. - 9 с.

18. Электромагнитный зонд для каротажа в нефтегазовых скважинах: пат. Рос. Федерация № 2583867; заявл. 20.02.15; опубл. 10.05.16. - Бюл. № 13. -7 с.

19. Математическое и физическое моделирование сигналов электромагнитного зонда для изучения макроанизотропии осадочных отложений / М.И. Эпов, В.Н. Глинских, В.Н. Еремин, М.Н. Никитенко, А.Н. Петров, И.В. Суродина, И.В. Михайлов // Геомодель 2017: 19-я конференция по вопросам геологоразведки и разработки месторождений нефти и газа. - Геленджик, 11-14 сентября 2017. - Статья 43809 (6 с.).

20. Electromagnetic tool for high-resolution logging: theoretical and experimental studies / M.I. Epov, V.N. Glinskikh, V.N. Eremin, M.N. Nikitenko, A.N. Petrov, I.V. Mikhaylov // SPE Russian Petroleum Technology Conference. - Moscow, October 16-18, 2017. - Paper SPE-187904-MS.

21. Совместная численная инверсия данных индукционных и гальванических каротажных зондирований в моделях геологических сред с осевой симметрией / И.В. Михайлов, В.Н. Глинских, М.Н. Никитенко, И.В. Суродина // Геология и геофизика. - 2017. - Т. 58. - № 6. - С. 935-947.

Поступила 21.03.2019 2.

\section{Информация об авторах}

Эпов М.И., доктор технических наук, академик РАН, главный научный сотрудник лаборатории многомасштабной геофизики Института нефтегазовой геологии и геофизики им. А.А. Трофимука СО РАН.

Михайлов И.В., научный сотрудник лаборатории многомасштабной геофизики Института нефтегазовой геологии и геофизики им. А.А. Трофимука СО РАН.

Глинских В.Н., доктор физико-математических наук, профессор РАН, заведующий лабораторией многомасштабной геофизики Института нефтегазовой геологии и геофизики им. А.А. Трофимука СО РАН.

Никитенко М.H., кандидат технических наук, старший научный сотрудник лаборатории многомасштабной геофизики Института нефтегазовой геологии и геофизики им. А.А. Трофимука СО РАН.

Суродина И.В., кандидат физико-математических наук, старший научный сотрудник лаборатории вычислительных задач геофизики Института вычислительной математики и математической геофизики СО РАН. 
UDC 550.832

\title{
ALGORITHMS OF DATA PROCESSING AND INVERSION FOR AN ELECTROMAGNETIC TOOL WITH TOROIDAL COILS WHEN STUDYING MACROANISOTROPIC PROPERTIES OF RESERVOIRS
}

Mikhail I. Epov',

EpovMl@ipgg.sbras.ru

Igor V. Mikhaylov',

MikhaylovIV@ipgg.sbras.ru

Viacheslav N. Glinskikh',

GlinskikhVN@ipgg.sbras.ru

Marina N. Nikitenko',

NikitenkoMN@ipgg.sbras.ru

Irina V. Surodina ${ }^{2}$,

sur@ommfao1.sscc.ru

\author{
A.A. Trofimuk Institute of Petroleum Geology and Geophysics SB RAS, \\ 3, Koptyug Avenue, Novosibirsk, 630090, Russia. \\ ${ }^{2}$ Institute of Computational Mathematics and Mathematical Geophysics SB RAS, \\ 6, Lavrentiev Avenue, Novosibirsk, 630090, Russia.
}

The relevance of the research is caused by the need to develop basic algorithms for processing and inversion of data from a new multi-coil multi-frequency multi-mode electromagnetic tool with toroidal coils designed for studying the electrical macroanisotropy of rocks, determining the saturation of reservoirs, identifying thinly bedded sandy-argillaceous oil-saturated intervals and fracture zones.

The main aim of the research is to develop basic algorithms for processing and inversion of data from the new electromagnetic tool with toroidal coils for studying the macroanisotropic properties of reservoirs with complex geological structure (thinly bedded, fractured).

Objects of the research are the signals of the new electromagnetic tool with toroidal coils.

Methods: finite-difference numerical simulation and comparative analysis of signals of the new electromagnetic tool with toroidal coils. Results. The authors have developed the basic algorithms for processing and inversion of data of the new electromagnetic tool with toroidal coils, among which: the algorithms of transforming the signals into the apparent resistivity and electrical anisotropy coefficient, selection of contrasting geoelectric boundaries, as well as software for numerical inversion with determination of the parameters of isotropic and anisotropic formations, taking into account the host medium. The computational algorithms are combined into a single computer program for quantitative interpretation of data from the new electromagnetic tool with toroidal coils. The algorithms are tested on noisy synthetic data. We have shown their efficiency when processing practical data from petroleum boreholes in the Volga-Ural oil and gas province. The investigations demonstrate that the new electromagnetic tool with toroidal coils has a high potential for use in geological sections of complex structure (thin-bedded, fractured).

Key words:

Geophysical well logging, toroidal coils, electrical resistivity, electrical anisotropy, numerical inversion, complex reservoir, oil saturation.

The research was supported by the RFBR grant (project no. 19-05-00595).

\section{REFERENCES}

1. Rytov S.M. Elektromagnitnye svoystva melkosloistoy sredy [Electromagnetic properties of a finely-layered medium]. Zhurnal eksperimentalnoy $i$ teoreticheskoy fiziki, 1955, vol. 29, no. 5, pp. $605-616$.

2. Alpin L.M. Opredelenie poperechnogo udelnogo soprotivleniya plastov po izmereniyam v skvazhinakh [Determination of transverse resistivity of reservoirs from measurements in wells]. $I z$ vestiya vuzov. Geologiya i razvedka, 1978, no. 4, pp. 81-95.

3. Alpin L.M., Velikin S.A. Opredelenie anizotropii po izmereniyam $\mathrm{v}$ skvazhinakh [Determination of anisotropy from measurements in wells]. Izvestiya vuzov. Geologiya i razvedka, 1983, no. 12, pp. 97-99.

4. Anderson B., Barber T., Habashy T. The Interpretation and Inversion of Fully Triaxial Induction Data: A Sensitivity Study. Transactions of the SPWLA 43 ${ }^{\text {rd }}$ Annual Logging Symposium. Oiso, Japan, June 2-5, 2002. Paper 0.
5. Wang G., Wu P., Barber T., Johnson C., Allen D., Kumar A., $\mathrm{Xu}$ W., Hayden R. Triaxial Induction Applications in Difficult and Unconventional Formations. Transactions of the SPWLA 53rd Annual Logging Symposium. Cartagena, Colombia, June 16-20, 2012. Paper G.

6. Gomes R., Denicol P., da Cunha A., de Souza M., Kriegshäuser B., Payne C., Santos A. Using Multicomponent Induction Log Data to Enhance Formation Evaluation in Deepwater Reservoirs from Campos Basin, Offshore Brasil. Transactions of the SPWLA 43kd Annual Logging Symposium. Oiso, Japan, June 2-5, 2002. Paper $\mathrm{N}$.

7. Karinsky A.D., Krasnoselskikh A.A. Modelirovanie karotazhnogo zonda, prednaznachennogo dlya opredeleniya koeffitsienta elektricheskoy anizotropii porod [Modeling logging tool designed to determine the coefficient of electrical anisotropy of rocks]. Geofizika, 2016, no. 1, pp. 26-33.

8. Arps J. Inductive Resistivity Guard Logging Apparatus Including Toroidal Coils Mounted on a Conductive Stem. US Patent 
no. $3305771,1967$.

9. Daev D.S. Ob istochnike electromagnitnogo polya pri vysokochastotnykh izmereniyakh $v$ skvazhine [On the source of the electromagnetic field in high-frequency measurements in a well]. Izv. AN SSSR. Ser. Fizika Zemli, 1968, no. 11, pp. 94-95.

10. Gianzero S., Chemali R., Lin Y., Su S., Foster M. A New Resistivity Tool for Measurement-While-Drilling. Transactions of the SPWLA $26^{\text {th }}$ Annual Logging Symposium. Dallas, Texas, USA, June 17-20, 1985. Paper A.

11. Bonner S., Burgess T., Clark B., Decker D., Orban J., Prevedel B., Luling M., White J. Measurements at the Bit: a New Generation of MWD Tools. Oilfield Review. April/July 1993. pp. 44-54.

12. Gianzero S. The Paradox of Anisotropy Revisited. The Log Analyst, 1999, vol. 40, no. 6, pp. 485-491.

13. Karinsky A.D. Resheniya priamykh zadach o pole toroidalnoy antenny $\mathrm{v}$ anizotropnoy srede [Solutions of direct problems on the field of a toroidal antenna in an anisotropic medium]. Fizika $\mathrm{Ze}$ mli, 2003, no. 1, pp. 9-20.

14. Karinsky A.D., Musatov A.A. Opredelenie vertikalnogo soprotivleniya plastov zondami s toroidalnymi antennami pri karotazhe v protsesse bureniya [Determination of vertical resistance of layers by tools with toroidal antennas during logging while drilling]. Novye idei $v$ naukakh o Zemle. Tezisy VI mezhdunarodnoy konferentsii [New ideas in earth sciences. Proc. VI International conference]. Moscow, 2003. Vol. 2, pp. 357.

15. Bittar M.S., Hu G. The Effects of Rock Anisotropy on LWD Toroidal Resistivity Sensors. Transactions of the SPWLA $45^{\text {th }}$ Annual Logging Symposium. Noordwijk, the Netherlands, June 6-9, 2004. Paper WW.

16. Ortenzi L., Dubourg I., van Os R., Han S., Koepsell R., Chow Yuk Ha S. New Azimuthal Resistivity and High-Resolution Imager Facilitates Formation Evaluation and Well Placement of Horizon- tal Slim Boreholes. Petrophysics, 2012, vol. 53, no. 3, pp. 197-207.

17. Epov M.I., Glinskikh V.N., Nikitenko M.N. Sposob izmereniya udelnoy electroprovodnosti $i$ electricheskoy makroanizotropii gornykh porod [The way to determine specific conductivity and electrical macroanisotropy of rocks]. Patent RF, no. 2525149, 2014.

18. Epov M.I., Eremin V.N., Petrov A.N., Glinskikh V.N. Electromagnitny zond dlya karotazha $v$ neftegazovykh skvazhinakh [Electromagnetic tool for logging in oil and gas wells]. Patent RF, no. 2583867, 2016.

19. Epov M.I., Glinskikh V.N., Eremin V.N., Nikitenko M.N., Petrov A.N., Surodina I.V., Mikhaylov I.V.Matematicheskoe i fizicheskoe modelirovanie signalov electromagnitnogo zonda dlya izucheniya makroanizotropii osadochnykh otlozheniy [Mathematical and physical simulation of responses of an electromagnetic logging tool for studying macroanizotropy of sedimentary deposits]. Geomodel 2017, 19-ya konferentsiya po voprosam geologorazvedki i razrabotki mestorozhdeniy nefti i gaza [Geomodel 2017. 19 conferenth in issues of geoexploration and development of oil and gas deposits]. Gelendzhik, 11-14 September 2017. Paper 43809 (6 p.).

20. Epov M.I., Glinskikh V.N., Eremin V.N., Nikitenko M.N., Petrov A.N., Mikhaylov I.V. Electromagnetic tool for high-resolution logging: theoretical and experimental studies. SPE Russian Petroleum Technology Conference. Moscow, October 16-18, 2017. Paper SPE-187904-MS.

21. Mikhaylov I.V., Glinskikh V.N., Nikitenko M.N., Surodina I.V. Joint inversion of induction and galvanic logging data in axisymmetric geological models. Russian Geology and Geophysics, 2017, vol. 58, no. 6, pp. 752-762.

Received: 21 March 2019.

\section{Information about the authors}

Mikhail I. Epov, Dr. Sc., RAS Academician, principal researcher, A.A. Trofimuk Institute of Petroleum Geology and Geophysics SB RAS.

Igor V. Mikhaylov, researcher, A.A. Trofimuk Institute of Petroleum Geology and Geophysics SB RAS.

Viacheslav N. Glinskikh, Dr. Sc., RAS Professor, head of laboratory of Multiscale Geophysics, A.A. Trofimuk Institute of Petroleum Geology and Geophysics SB RAS.

Marina N. Nikitenko, Cand. Sc., senior researcher, A.A. Trofimuk Institute of Petroleum Geology and Geophysics SB RAS.

Irina V. Surodina, Cand. Sc., senior researcher, Institute of Computational Mathematics and Mathematical Geophysics SB RAS. 